\title{
Fingerprinting groundwater pollution in catchments with contrasting contaminant sources using microorganic compounds
}

\author{
Marianne E Stuart ${ }^{*}$, Dan J Lapworth ${ }^{1}$, Jenny Thomas ${ }^{2}$ and Laura Edwards ${ }^{3}$ \\ ${ }^{1}$ British Geological Survey, Maclean Building, Wallingford OX10 8BB \\ ${ }^{2}$ Environment Agency, Kings Meadow House, Reading RG1 8DQ \\ ${ }^{3}$ Environment Agency, Howbery Park, Wallingford OX10 8BD \\ * Corresponding author: mest@bgs.ac.uk
}

\begin{abstract}
Evaluating the occurrence of microorganics helps to understand sources and processes which may be controlling the transport and fate of emerging contaminants (ECs). A study was carried out at the contrasting instrumented environmental observatory sites at Oxford, on the peri-urban floodplain gravel aquifer of the River Thames and Boxford, in the rural valley of the River Lambourn on the Chalk aquifer, in Southern England to explore the use of ECs to fingerprint contaminant sources and flow pathways in groundwater. At Oxford compounds were typical of a local waste tip plume (plasticisers and solvents but also barbiturates and $\mathrm{N}, \mathrm{N}$-diethyl-m-toluamide (DEET)) and of the urban area (plasticisers and mood-enhancing drugs such as carbamazepine). At Boxford the results were different with widespread occurrence of agricultural pesticides, their metabolites and the solvent trichloroethene, as well as plasticisers, caffeine, butylated food additives, DEET, parabens and trace polyaromatic hydrocarbons $(\mathrm{PAH})$. Groups of compounds used in pharmaceuticals and personal care products of different provenance in the environment could be distinguished, i) historical household and medical waste, ii) long-term household usage persistent in groundwater and iii) current usage and contamination from surface water. Co-contaminant and degradation products can also indicate the likely source of contaminants. A cocktail of contaminants can be used as tracers to provide information on catchment pathways and groundwater/surface water interactions. A prominent feature in this study is the attenuation of many EC compounds in the hyporheic zone.
\end{abstract}

Key words: plasticisers, pharmaceuticals, pesticides, floodplain, peri-urban, hyporheic zone 


\section{Introduction}

A diverse array of synthetic organic compounds is used worldwide in large quantities for the production and preservation of food, for industrial manufacturing processes and for human and animal healthcare. In the last few decades there has been a growing interest in the occurrence, fate and potential toxicity of these contaminants in the terrestrial and aquatic environment (Daughton and Ternes, 2000; Halling-Sørensen et al., 1998; Kümmerer, 2009; Schwarzenbach et al., 2006; Stan et al., 1994; Stan and Linkerhägner, 1992). The contamination of groundwater is relatively poorly understood compared to other freshwater resources (Pal et al., 2010).

Included in this concern are so called "emerging contaminants", microorganics previously not considered or known to be significant in groundwater, which are now being detected as analytical techniques improve and which have the potential to cause adverse ecological or human health effects (Lindsey et al., 2001; Petrović et al., 2006). These include substances that have probably long been present in the environment but whose presence is only now being elucidated (Daughton, 2004). Richardson and Ternes (2011) reviewed recent analytical developments in the emerging contaminant context.

Microorganics encompass a wide array of compounds (as well as their metabolites and transformation products): pharmaceuticals and personal care products (PCPs), pesticides, veterinary products, industrial compounds/by-products and food additives. Because of the vast number of compounds, many studies have selected determinands according to priority lists taking into account consumption and predicted environmental concentrations as well as ecotoxicological, pharmacological and physicochemical data (Besse and Garric, 2008; Celiz et al., 2009; Crane et al., 2008; Fent et al., 2006; Hilton et al., 2003; Huschek et al., 2004). A systematic review of emerging contaminants in groundwater, by Lapworth et al. (2012) highlighted the widespread contamination of resources worldwide. Stuart and Lapworth (2013) also highlight the occurrence of transformation products of these compounds in groundwater.

It has been recognised that the range of contaminants present in groundwater is driven by activity at the surface. Wastewaters are the main sources of organics in the environment and surface waters therefore contain the greatest loads. There have been a large number of studies investigating the fate of microorganics in groundwater following the infiltration of 
wastewater to the ground (Clara et al., 2004; Drewes et al., 2003; Gasser et al., 2010; Glassmeyer et al., 2008; Grünheid et al., 2005; Heberer and Adam, 2004; Heberer et al., 1997; Katz et al., 2009; Rabiet et al., 2006; Sacher et al., 2001; Snyder et al., 2004).

In urban areas groundwater is likely to be impacted by pollutants from sewage, industrial activities as well as historical waste management practices. Diffuse leakage from reticulated sewerage systems poses a significant pollution risk as it bypasses natural attenuation mechanisms in the subsurface (Ellis, 2006). Wastewater may contain pharmaceuticals, household detergents, fragrances and flavourings and plant and animals steroids. Hospital wastewater forms an important source of contaminants including a wide range of pharmaceuticals (Verlicchi et al., 2010; Watkinson et al., 2009). Industrial compounds include solvents, detergents, flame retardants and polyaromatic hydrocarbons (PAH).

In rural areas we might anticipate pesticides and veterinary medicines related to agriculture and animal waste. Boxall et al. (2004) discuss the risks to the environment from a range of veterinary medicines. Pesticides have been detected at trace concentrations in groundwater worldwide since the 1980s and remain important contaminants (Arias-Estévez et al., 2008; Baran et al., 2008a; Close, 1996; Gilliom, 2007; Kolpin et al., 2000; Tappe et al., 2002; Walls et al., 1996; Zeng et al., 2011). The problem of persistent transformation products produced from partial degradation of pesticides in groundwater has also been recognised (Galassi et al., 1996; Somasundaram and Coats, 1991) and a wide range of such products have been identified in groundwater (e.g. Jacobsen et al., 2005; Kjaer et al., 2005; Kolpin et al., 2004). Risk assessment of pesticide transformation products in groundwater has been reviewed by Stuart et al. (2012).

Municipal solid waste leachate contains a wide range of organic compounds (Christensen et al., 2001; Sabel and Clark, 1984). Slack (2007) reviewed the detections of xenobiotic compounds in leachate including halogenated and aromatic hydrocarbons, phenols (including bisphenol A), alkyl phenols (including nonyl phenol), pesticides, phthalates, pharmaceuticals, sulfonates, sulfones and sulfonamides (including n-butylbenzenesulfonamide (BBSA)), pyridines (including nicotine), carboxylic acids, alcohols, ethers and ketones, as well as caffeine, benzthiazoles and anilines. Barnes et al. (2004) and Buszka et al. (2009) found a range of microorganics in groundwater downgradient of landfills including detergents, antioxidants, fire retardants, plasticisers, antibiotics, ant-inflammatories, barbiturates, caffeine and cotinine. 
Zheng et al. (2013) describe the use of organic water pollutant fingerprints to track the movement of industrial materials. Key target compounds were plasticisers, PCBs, PBDEs and steroids from the electronics, plastics, and biomedical industries.

Building on the documented contamination from different contaminant sources, the aims of the work described here were to investigate the use of screening for microorganic compounds in groundwater as a novel tool for understanding groundwater movement and transport processes in complex hydrogeological settings. This was addressed by screening for a very broad range of microorganics present from a range of sources at two UK sites with contrasting sources of contamination and showing how the microorganic fingerprint can help in understanding site hydrological settings. Importantly, this work was carried out at two sites where previous work had characterised the hydrogeology of the sites, and suitable borehole arrays were available for microorganic sampling (Gooddy et al., 2007; Allen et al., 2010; Macdonald et al., 2012). The study selected sampling points within each observatory: i) to collect samples from different depths, ii) to characterise microorganic pollution from a range of different potential sources, typical of lowland UK catchments, iii) to investigate the evolution of microorganic pollution along flow lines and with depth within the observatories, iv) to investigate to role of the hyporheic zone in attenuating microorganic contaminants and v) to explore the benefits of using broad screening GCMS methods for fingerprinting microorganic contamination in groundwater.

\section{Study sites}

\subsection{OXFORD OBSERVATORY}

The peri-urban Oxford Observatory centres on the Port Meadow, an ancient grassland still used for communal grazing in the floodplain of the River Thames to the northwest of Oxford. This meadow is bounded on the west by the Thames and to the east by the Oxford Canal (Figure 1a). The River Thames flows from northwest to southeast, regularly flooding areas of the Port Meadow. To the west of the Thames is an area of artificially-drained agricultural land. The study area also includes the former Burgess Field waste tip located to the east of Port Meadow and the urbanised higher ground to the east of the floodplain (Macdonald et al., 2012). Burgess Field was used as a domestic waste dump from 1937 to 1980 and is now covered by grassland and woodland. At the southern end of Burgess Field lies an allotment site which was once a Victorian waste tip. 
The superficial deposits of the floodplain comprise alluvium underlain by 4 to $5 \mathrm{~m}$ of river terrace gravels (the Northmoor Sand and Gravel Member) which form the shallow aquifer (Figure 1b). To the east of the canal the ground surface is a few metres higher and older terrace gravels are present (the Summertown-Radley Sand and Gravel Member). To the west of the Seacourt Stream the ground rises steeply. The bedrock beneath the entire area is the poorly-permeable Oxford Clay Formation.

Groundwater flow in the superficial deposits is from northeast to southwest (Figure 1a). Gradients to the east of the Thames are relatively shallow, contrasting with the west where gradients are steep especially adjacent to the river. The Thames is not strongly hydraulically connected to the aquifer. In dry periods, as in Figure 1a, the controlled river levels are higher than the surrounding groundwater in the south of the area and there may be some flow eastwards from the river. There is potential for groundwater to flow from east to west beneath the river through the gravels (Macdonald et al., 2012).

The Observatory has a comprehensive monitoring network including two transects of multilevel piezometers in the superficial deposits down gradient of the waste tip and boreholes across the site area and in the periphery of the waste tip. Table 1 gives details of the sites used in this study. Macdonald et al. (2012) divide the study area into zones depending on geographical, hydrogeological and hydrochemical setting:

- PUFP - peri-urban flood plain east of the Thames and upgradient of the waste tip

- PUFP2 - peri-urban flood plain east of the Thames and influenced by the waste tip plume

- PUFP2 tip - sites in PUFP2 within the waste tip boundary

- $\quad$ URB - urban area to the east, upgradient of the floodplain and waste tip

- AGR - floodplain to the west of the Thames with agricultural land use.

- $\mathbf{S W}$ - surface water.

In this study the PUFP2 zone was divided into shallow (C) and deep (D) zones. Existing monitoring data demonstrate significant spatial variations between these areas from localised sources of contamination. The waste tip has a significant influence with elevated concentrations of major ions, ammonium, boron and organic carbon immediately downgradient (Lapworth et al., 2013). In general leachate-derived compounds decrease with 
distance from the tip. There is evidence of stratification within the plume with less attenuation of major ions in the deeper horizon (Macdonald et al., 2012).

\subsection{BOXFORD OBSERVATORY}

This rural site is located on the River Lambourn, a predominantly groundwater-fed river which drains part of the chalk of the Berkshire Downs in south east England along a mostly linear, incised valley (Allen et al., 2010). Ground to the north of Westbrook Farm is used for grazing and there is a modern cattle shed sited to the northwest of the sampling site (Figure 2a). Land to the east is arable and to the west is used for rural housing. There are a number of sewage outfalls along the River Lambourn; to the west of the site is a large discharge serving Great Shefford and there is a smaller one close to Site LO1.

The site is underlain mainly by the Seaford Chalk, part of the former Upper Chalk (Figure 2b). Valley fill comprises river terrace deposits consisting of coarse-grained gravel with small amounts of sand, silt and clay. These gravels are typically 3-4 m thick although there is a high degree of spatial heterogeneity and hydraulic complexity; at borehole A only sand is present. The basal 1-2 m often includes a high proportion of reworked chalk which can reduce the permeability. The alluvial cover on the underlying gravels is up to $2.7 \mathrm{~m}$ thick and comprises peat, clay, silt sand and gravel merging with head and slope wash on the valley flanks.

Regional groundwater flow is to the southeast along the line of the valley. Groundwater contours suggest that groundwater has little interaction with the river either directly or via the gravels. There appears to be increased permeability under and near the river. Heads in the gravel are consistently lower than in the underlying chalk implying a poor connection.

The Boxford site has a series of boreholes close to the line of the River Lambourn, intersecting the gravels, chalk, as well as boreholes driven into the base of the streambed in the hyporheic zone. The sites used in this study are shown in Table 1. Close to Westbrook Farm there is evidence from chloride and sulphate monitoring data of ternary mixing between the river, the chalk aquifer and the superficial aquifer, including an end member from a site close to the cattle barn (Allen et al., 2010). Sample zones for Chalk and superficial deposits were further divided into $\mathrm{W}$ (west with farm influence) and $\mathrm{E}$ (east - downstream).

Sample zones were classified into:

- Superficial W - Superficial deposits in the western part of the area 
- $\mathbf{S W}$ - Surface water

- $\quad \mathbf{H Z}$ - Hyporheic zone

- Chalk W - Chalk aquifer in the western part of the area

- Superficial E - Superficial deposits in the eastern part of the area

- Chalk $\mathbf{E}$ - Chalk aquifer in the eastern part of the area

\section{Methodology}

\subsection{SAMPLING AND ANALYSIS}

Sampling sites were selected to provide a representative coverage of land use zones and aquifers depths. For each site two visits were made at periods of contrasting water levels between July 2011 and August 2012. Due to atypical weather over this period water levels were higher in August 2012 than in January 2012.

Samples were collected using a standardised procedure for each round of sampling which is briefly described below. Boreholes were purged using a submersible pump to remove at least 3 borehole volumes prior to sampling. Field parameters, dissolved oxygen, pH, electrical conductivity and redox potential were monitored in a sealed flow-through cell to ensure that stable values were also obtained prior to sampling for microorganics. A peristaltic pump and PTFE tubing was used to sample for microorganics, this tubing was acid washed (10\% nitric acid) and rinsed with ultrapure water prior to sampling. Glass 1-L bottles with PTFE cap liners were used to collect samples, unfiltered, for the targeted GCMS analysis. A mixture of glass and HDPE bottles were used to collect the samples, also unfiltered, for the quantitative analysis, as well as the LCMS suite. These bottles were provided by the Environment Agency National Science Laboratory, and comply with their protocols for sample storage. Samples were stored in the dark at $4{ }^{\circ} \mathrm{C}$ at BGS prior to analysis. Storage time was minimised prior to sample processing and analysis to reduce the potential for microbiological breakdown of contaminants.

Blank samples were collected using the same protocol as the other samples and submitted 'blind' to the laboratories for analysis. For these blank samples ultrapure grade water was pumped from a clean glass beaker and the bottles filled and stored with the other samples prior to analysis. Samplers were careful not to apply lotions or creams on the sampling days 
to avoid contamination of samples. Gloves were not worn as these can readily contaminate samples with plasticisers and hands were rinsed under the pump outflow before sample collection. Particular care was taken not to touch the neck of the bottle, or inside the caps when handing the samples for the same reason. Protective clothing, comprising, gloves and impermeable overalls were necessary when sampling waters from the base of the landfill for health and safety reasons.

Samples were analysed by the National Laboratory Service using a semi-quantitative GC-MS multi residue targeted screening method. This uses a target compound database of almost 1000 compounds with a detection limit of $0.01 \mu \mathrm{g} / \mathrm{L}$ achieved for about $75 \%$ of determinands. Poorer limits were found for some polar compounds and some with multiple isomers. At both sites additional analyses for a number of suites were made on one of the rounds for QA purposes. These comprised volatile compounds (VOCs), PAHs, acid herbicides and "uron" pesticides. For most determinands these suites had much lower detection limits than the screening method and comparable data were only obtained for trichloroethene and some PAH where good agreement was observed. These data are not described further.

\section{Results}

\subsection{OXFORD OBSERVATORY}

\subsubsection{Frequency and concentration}

The study was successful in obtaining samples which did not appear to be contaminated during collection and which were able to identify contaminants from multiple sources within the peri-urban study area. At least 1 organic micropollutant was detected at each site and both priority pollutants and emerging contaminants were found.

In the first round in 2011 a total of 26 compounds were detected in groundwater outside of the waste tip with the plasticiser BBSA being both the most frequently detected compound and at the highest maximum concentration (Table 2). Within the waste tip site an overlapping range of compounds was detected additionally including bisphenol A (resin precursor), bis(2-ethyl hexyl)phthalate (DEHP - plasticiser), chlorobenzenes (industrial intermediates/solvents), methaqualone (hypnotic/sedative drug)), tributyl phosphate (plasticiser) and further PAH. A number of the compounds detected are priority substances 
established under the WFD namely, trichloroethene, t-octyl phenol, bisphenol A, DEHP anthracene and fluoranthene. Metaldehyde (molluscicide) concentrations within the waste tip were recorded at $5.5 \mu \mathrm{g} / \mathrm{L}$.

Maximum concentrations and detection frequencies for the second round are also shown in Table 2. In all 43 separate compounds were semi-quantitatively identified and the greatest concentrations were seen for BBSA, 1,4-dioxane (solvent stabiliser), metaldehyde, di-n-butyl phthalate (DBP) and DEHP). BBSA was also the most frequently detected compound followed by 2,4,7,9-tetramethyl-5-decyne-4,7-diol (TMDD-non ionic surfactant), dimethyl phthalate (DMP), metaldehyde and N,N-diethyl-m-toluamide (DEET-insect repellent).

\subsubsection{Areal distribution- fingerprinting}

Plots of the median concentrations for the most frequently detected compounds and the total number of compounds detected in each zone for 2011 and 2012 are shown in Figures 3 and 4. The ubiquitous BBSA has been excluded.

AGR - In 2011 the single sampling point in AGR was characterised by low concentrations of DBP, 1,4-dioxane, TMDD, metaldehyde and carbamazepine. In 2012 MF15 contained different phthalates, cyclohexanone and crotamitron as well as TMDD and 1,4-dioxane.

SW - The Thames contained gabapentin and TMDD at $\mu \mathrm{g} / \mathrm{L}$ concentrations and lower concentrations of DEET and TTT and variously carbamazepine, crotamitron, caffeine, 1,4dioxane, cyclohexanone and bisphenol A.

PUFP2C- shallow gravels - Two of the three shallow piezometers contained over $20 \mu \mathrm{g} / \mathrm{L}$ 1,4-dioxane and also trichloroethene. Other components detected were metaldehyde, paraldehyde, pentobarbital, butabarbital, TMDD and phthalates. Traces of DEET, crotamitron, gabapentin were detected mainly in PTM31C nearest the waste site.

PUFP2D- deeper gravels - This zone is similar to the shallow piezometers but with higher concentrations of 1,4-dioxane, trichloroethene, metaldehyde and pentobarbital observed, probably due to the greater permeability and hence solute migration in the deeper gravels. DEP as well as DMP is detected and DEET is present in all three sites.

PUFP2- tip - A large number of individual compounds were detected with 25 in 2011 and 31 in 2012. The largest difference observed was the detection of high concentrations of 1,4dioxane in 2012 but none in 2011. The three points, GBH 3, 5 and 9 showed a distinctive fingerprint for both sets of samples with detections of metaldehyde, pentobarbital 4-octyl 
phenol, DEET, bisphenol A, chlorobenzene, butabarbital paraldehyde, TMDD, diphenylamine, methaqualone, TTT, crotamitron and cyclohexanone. A range of phosphates (such as triphenyl, tris-(1,3-dichloroisopropyl and tributyl) and phthalates were found with different members found on the two visits. There were some minor differences with $2(3 \mathrm{H})$ benzothiazolone and 2-chlorophenyl isocyanate found in 2011 and BHT, BHA and benzophenonein 2012. The greatest number of compounds (28) were found in GBH9, and the least in GBH3 (18).

URB - The two sites in this area gave differing results. OX13 contained DMP and DEP and triphenyl phosphate in 2011 only. OX14 contained a wider range of compounds with low concentrations of TMDD, gabapentin, carbamazepine, t-octyl phenol, DEET and TTT, plus DEET, crotamitron and PAH in 2012.

PUFP - The single sampling point used in this study in this area (PTM11) contained no detectable compounds other than the ubiquitous BBSA and a single low detection of cyclohexanone.

\subsection{BOXFORD OBSERVATORY}

\subsubsection{Frequency and concentration}

A smaller range of compounds was detected at Boxford compared to Oxford, with 33 compounds found in the first round in January 2012. BBSA and DEPH were detected at the highest concentrations, at maximum concentrations of 240 and $46 \mu \mathrm{g} / \mathrm{L}$ respectively (Table 3). Other compounds detected with maximum concentrations above $0.1 \mu \mathrm{g} / \mathrm{L}$ were bisphenol $\mathrm{A}$ and DEP, the industrial intermediate 2-chlorophenyl isocyanate and trichloroethene. Also in this group were emerging contaminants, the food additive BHT and caffeine, three parabens and DEET appear just below this in the distribution. BBSA, bisphenol A trichloroethene and 2-chlorophenyl isocyanate were also the most frequently detected in January 2012 followed by atrazine, DEHP and caffeine. Fluoranthene and pyrene were detected at several sites whereas a range of other PAH was only found at one site.

The results for the second round (August 2012) sampling are also summarised in Table 3. These are conspicuously different from the January survey, with many fewer compounds detected. Results for BBSA, trichloroethene DEHP and DMP were similar for both dates. However, many emerging contaminants were not detected at all including 2-chlorophenyl 
isocyanate, caffeine and the parabens. Bisphenol A was only detected in $50 \%$ of the samples and these were also few detections of PAH.

\subsubsection{Areal distribution -Fingerprinting}

The distribution of microorganics varied with location and between the superficial and chalk aquifers and also between the two sampling rounds (Figures 5 and 6). Atrazine was ubiquitous but slightly higher in both the gravels and the chalk at the east of the site. Trichloroethene, monuron and propazine were also widespread.

Superficial W - In the first round PAH were found in PL26Y, the nearest site to the cattle barn. In all 17 compounds were detected including DEHP, bisphenol A, 2-chlorophenyl isocyanate, 2-ethyl salicylate and parabens, as well as caffeine. As distance from the barn increased the number of compounds detected was reduced. Atrazine was not detected at 3 of the four sites. In the second round no parabens, PAH or 2-chlorophenyl isocyanate were found but instead BHT and octyl phenol.

SW - In the first round the river contained caffeine, TAED, bisphenol A and PAH, with no phthalates or atrazine. In the second only bromoform and DEET were detected.

HZ - The hyporheic zone had the fewest detections in both rounds. In the first round low concentrations of trichloroethene, 2-chlorophenyl isocyanate and bisphenol A were found with no phthalates, parabens or caffeine. In the second 2-chlorophenyl isocyanate was absent

Chalk W - Overall more compounds were detected in the chalk than in the superficials. In the first round PL26D1 had the greatest number of detections. This zone also had the highest bisphenol A, DEHP and DEP as well as caffeine, BHT, DEET, parabens and some PAH traces. In the second round caffeine, BHT, DEET, parabens and PAH were not found.

Superficial E - In this zone fewer compounds were detected than for superficial W. These were mainly similar to superficial $\mathrm{W}$ but with no parabens or $\mathrm{PAH}$, but atrazine, desethyl atrazine and bromacil.

Chalk $\mathbf{E}$ - In the first round this zone had the same main components as the superficial $\mathrm{E}$ but both 2-chlorophenyl isocyanate and atrazine and its desethyl metabolite were detected as well as caffeine. In the second round 2-chlorophenyl isocyanate, parabens and desethyl atrazine were not found. 


\section{Discussion}

\subsection{SUCCESSFUL APPLICATION OF SCREENING TECHNIQUE}

The data presented here confirm our premise that groundwater from different settings within complex catchments has a fingerprint of microorganic compounds which can be used to help to understand hydrological settings. Here two very well-investigated sites where the setting was already understood were successfully used to demonstrate the proposed approach.

Key results are the data shown in Figures 3-6. These clearly demonstrate the microorganic fingerprint, both in terms of the number of compounds detected and in the identity and concentration of the main components. There are considerable contrasts between the two sites and for different areas within each site.

At Oxford five or more microorganics were found all zones except the upgradient PUFP with the largest number in the tip area. The tip area and the plume contained compounds potentially found in industrial, domestic and medical waste, surface water contained pharmaceuticals and caffeine, the agricultural area has been shown to contain pesticides contained a mixture of surface water and plume components. Pharmaceuticals were also detected in the urban area.

At Boxford during low water levels zones at the west of the site contained significantly more compounds than the downstream zones, consistent with wastewater inputs, including parabens and caffeine. The highest concentrations were found in the Chalk and agricultural pesticides were widespread. At high water levels, far fewer compounds were found and the zones were less distinct.

\subsection{CONFIDENCE IN GCMS SCANS}

All sites in this study contained at least one microorganic compound that could be characterised by GCMS screening and the LCMS method indicated that there were probably others. Where compounds could be detected by more than one method, the results were in reasonable agreement. Trichloroethene was the only compound with sufficient above detection limit concentrations estimated by both methods to allow a coefficient of regression to be calculated $\left(\mathrm{R}^{2}=0.99\right)$. Crossplots for trichloroethene, atrazine and individual PAH are provided in the supplementary information.

Some confidence was also provided by the good correlation at Oxford of both the number and identity of the suite of compounds between the two surveys. The PUFP area had very few 
detections and both shows this area relatively unimpacted and gives us confidence that detections at other sites have some validity e.g. BBSA and DEET. This is in agreement with the blanks. Only two compounds were detected overall in the field blanks and on two of the three blank results reported concentrations were very low. At Boxford however, this correspondence is much less pronounced with only 12 compounds being found on the second visit compared to 33 on the first, due to the very different hydraulic conditions.

Although this is semi-quantitative screening data we have confidence that the overall conclusions are valid, since they rely on an aggregate of data not on individual values.

\subsection{DISTRIBUTION OF COMPOUND GROUPS}

Many plasticisers and related compounds have become ubiquitous in the environment and some, such as the phthalates, bisphenol A are recognised as priority substances (EC, 2008; $\mathrm{EC}, 2011)$. Others such as BBSA, DEET and 2-chlorophenyl isocyanate are not as yet categorised. These compounds were widely detected in both the peri-urban and predominantly rural environments.

Pharmaceuticals and PCPs are also widely detected but the pattern at individual sites differs. We can differentiate between groups of compounds of different provenance at Oxford:

- Compounds present in historical household and medical waste and found in groundwater in the waste tip and the groundwater plume at Oxford: paraldehyde, pentobarbital, butabarbital and methaqualone. Paraldehyde was commonly used up to the 1960s in psychiatric wards and to treat delirium tremens (Thompson et al., 1975). Methaqualone use peaked in 1970s as a hypnotic and treatment for insomnia (Parsons and Thomson, 1961). Pentobarbital and butabarbital are barbiturates which were used to treat insomnia.

- Compounds in household usage and persistent enough in the environment to be present in groundwater at Boxford and the urban area at Oxford: paracetamol, methyl and propyl parabens, gabapentin and carbamazepine (Bazin et al., 2010; KasprzykHordern et al., 2008; Lam et al., 2004).

The herbicide atrazine has been the most ubiquitous pesticide found in groundwater for two decades and remains common in groundwater worldwide (Baran et al., 2008b; Ritter, 1990; Tappe et al., 2002; Walls et al., 1996) despite its progressive withdrawal from use. This is highlighted at Boxford where slightly higher concentrations are associated with the east end 
of the site where there are arable fields where use was permitted up until 2004. Its desethyl metabolite was also found. Atrazine was not found at Oxford where sources are predominantly urban and it has been withdrawn for non-agricultural use since 1993. There were indications of the presence of diuron, also withdrawn for use as an atrazine replacement. Metaldehyde was found only in the PUFP2 area in Oxford perhaps derived from its use on the allotments and from historical disposal.

Of compounds which are consumed and excreted to wastewater, caffeine was found in surface water at Oxford and throughout the site other than the hyporheic zone at Boxford during January 2012. It was not detected at Boxford in August 2012. The food additives BHT and BHA were found only at Boxford.

\subsection{UNDERSTANDING PROCESSES}

Evaluating a full suite of microorganics, including pesticides and priority substances has been an important aspect of this study and helps to elucidate the sources and processes at a site which may be controlling the transport and fate of microorganic contaminants. Important aspects can include; contaminant source, HZ fate and migration pathways.

Co-contaminant and degradation products can indicate the likely source of contaminants. For example degradation products from some substances originating in the Oxford waste tip were seen in the plume but not always in the waste; 1,4-dioxane and cis-1,2 dichloroethene are both probably related to trichloroethene, as co-contaminants or anaerobic degradation products (Bagley and Gossett, 1990; Parsons et al., 1984; Zenker et al., 2004). At Boxford parabens, caffeine, bisphenol A and DEHP were present in higher concentrations at the western end of the site close to the cattle shed, suggesting that they are derived from the farm or from the upstream STW whilst atrazine and its desethyl metabolite were more common lower down the site near the arable area. This is consistent with the elevated organics detected using fluorescence spectroscopy at these sites (Lapworth et al., 2009).

The widespread detection of a range of plasticisers may be in part related to the use of plastic casing in some of the sampling points.

Contaminants can provide information on groundwater/surface water interactions. At Oxford some substances from the plume have been detected in MF15 e.g. DnBP, 1,4-dioxane, and metaldehyde, suggesting some components of the plume migrate beneath the Thames. But in general most plume components are not detected in boreholes located on the other side of the 
river, and do not presumably travel further than the river-groundwater interface. The flux of contaminants was such that any compounds were diluted by the river water below method detection limits. Contaminants possibly from the Thames have also been detected in MF15 e.g. carbamazepine, suggesting a significant degree of interaction between the surface water and groundwater body at this location. At Boxford most compounds are distributed between the gravels and the chalk- but there are generally more compounds detected in the chalk. Different concentrations suggest that the superficial and chalk aquifers are not always acting in continuity.

A prominent feature is the absence of many compounds in the HZ. In January 2012 few compounds were detected at Boxford namely BBSA, TCE, bisphenol A, 2-chlorophenol and isocyanate. Caffeine, DEET, DEHP and the parabens were all absent. This may suggest that the $\mathrm{HZ}$ is an active zone where organics are less persistent. Figure 7 shows depth order plots for surface water, the $\mathrm{HZ}$ and the chalk for the Boxford site, together with adjacent gravels. Figure 7a shows that the total number of compounds detected is much higher in the chalk than the gravels or surface water with the HZ being consistently low. For bisphenol A, shown in Figure $7 \mathrm{~b}$, there is some evidence of influence from the chalk in the deeper $\mathrm{HZ}$ piezometers, PL26T and PL26S whilst PL26R is similar to the river. Allen et al. (2010) used major ions, including sodium, chloride, sulphate and nitrate, in their study of this site to demonstrate that water quality in the HZ typically lies between the river and the Chalk.

The role of the $\mathrm{HZ}$ in the movement and attenuation of natural dissolved organic carbon between groundwater and surface water has been long recognised (Boulton et al., 1998), as has the potential of river bank filtration for the removal of organic pollutants (Tufenkji et al., 2002). A number of studies have shown the persistence of microorganics from surface water into groundwater, albeit at lower concentrations (Banzhaf et al., In press; Heberer et al., 2008; Lewandowski et al., 2011). Engelhardt et al. (2011) used artificial sweeteners and Xray contrast media as tracers for $\mathrm{HZ}$ exchange but found them to have been attenuated within $200 \mathrm{~m}$ of the river bank. These studies were generally on lowland rivers and the apparent removal of organic pollutants within the $\mathrm{HZ}$ of a Chalk stream was surprising.

Generally concentrations of diffuse pollutants such as nitrate and pesticides rise during periods of high water level as additional mass is transported from the surface and unsaturated zone. For point sources the reverse can be true with a fixed size source diluted by additional recharge. The pattern of detection of contaminants was very similar between the two visits at 
Oxford in terms of determinands found, frequencies and concentrations. At Boxford the behaviour is different with generally lower concentrations of contaminants found in the August visit and all being established contaminants rather than emerging ones. This would suggest that emerging contaminants at Boxford are derived from point sources.

An alternative explanation is that these results could be due to groundwater travel times and mixing processes. At Oxford many of the pollutants in the floodplain are derived from the waste tip leachate plume. At this site, the residence time indicators $\mathrm{CFC}$ and $\mathrm{SF}_{6}$ showed a complex pattern, due to both the probable presence of CFC-12 in the waste tip, which gives values of post modern in PTM31C and D, and to degradation of CFC12 and to a greater extent CFC-11 in anaerobic water in the leachate plume (Macdonald et al., 2012; Macdonald et al., 2013). The $\mathrm{SF}_{6}$ data suggested that groundwater is older at depth and away from the river with a mean age of groundwater in the floodplain in the order of 20 years and contains about $50 \%$ modern water. The aquifer is thin and shallow so there is no dilution by underlying better quality water. The microorganics may indicate a steady historical leachate source which is periodically diluted with modern recharge or surface water which is of different, and generally better, quality.

At Boxford $\mathrm{CFC}$ and $\mathrm{SF}_{6}$ measurements contributed to a conceptual flow model with piston flow away from the river where the unsaturated zone is significant, exponential mixing closer to the river where the unsaturated zone is thinner as progressively younger water recharges and surface water/groundwater interaction in the vicinity of the river, with a modern water content of up to $80 \%$ (Gooddy et al., 2006). Groundwater has a mean residence time of perhaps 23 years in a piezometer open between 50 and $100 \mathrm{~m}$ below the surface, the deepest in the study. This study also suggested chalk groundwater in PL26D1 to be about 20 years old and in the overlying gravel in PL26D2 about 14 years. There was also evidence of groundwater/surface interaction below $10 \mathrm{~m}$. In this case a possible explanation of the behaviour of the microorganics is that the relatively old water in the chalk at depth was originally of good quality and that a small component of recharge from the surface or lateral flow from surface water is of very variable quality and is the source term. In both cases the mean age of groundwater may therefore be one or two decades and indicates the long-term persistence of some organic compounds in the subsurface. 


\subsection{WIDER APPLICATION}

The literature as reviewed in the introduction would suggest that groundwater would be likely to contain a large number of trace organic compounds. However, relatively few studies have attempted to use these compounds as tracers or fingerprinting tools to help understand the impact of a diverse range of contaminant source terms at the subcatchment scale. For example, Van Stempvoort et al. (2011) and Buerge et al. (2009) used the artificial sweetener acesulfame and Hunt et al. (2010) ionic detergents, flame retardants, and cholesterol as tracers for domestic wastewater and Zheng et al. (2013) used plasticisers, PCBs, flame retardants and steroids for industrial compounds. The proposed screening tool for fingerprinting groundwater takes this a step further as a broad range of contaminants from a number of different sources can be evaluated in a single analysis. This avoids the problem of a distorted view of environmental occurrence and processes inherent in targeted environmental monitoring (Daughton 2004). Individual contaminants can of course be quantified by a specific method in any follow-up work.

Our hypothesis that groundwater from a particular area in the catchment would have a distinctive organic fingerprint is supported by the data from the two sites studied. These have already been characterised using hydraulic and other water quality information. It would be reasonable to suppose that the approach would have a wider application for understanding spatial and temporal changes in sources of contamination, groundwater flow and contaminant transport processes in less well-characterised settings.

\section{Conclusions}

Evaluating the occurrence of a wide range of microorganics in groundwater helps to understand sources and processes which may be controlling the transport and fate of emerging contaminants. Xenobiotic microorganics were detected in groundwater at all sites in two contrasting study areas.

At Oxford the compounds detected could be used to characterise different sources within the peri-urban area: the anticipated plasticisers and solvents, but also barbiturates and DEET, associated with the plume from a local historical waste tip, and plasticisers and mood enhancing drugs such as carbamazepine from the urban area. Some evidence of a limited hydraulic connection between the river Thames and groundwater was observed. 
At Boxford the results were different with widespread agricultural pesticides, their metabolites and the solvent trichloroethene, as well as plasticisers, and also caffeine, butylated food additives, DEET, parabens and trace PAH. The relative composition varied with cattle barn or agricultural influence.

Groups of compounds used in pharmaceuticals and personal care products of different provenance in the environment could be distinguished, historical household and medical waste, long-term household usage persistent in groundwater and current usage and found in surface water.

Evaluating a cocktail of microorganics, including pesticides and priority substances, has been an important aspect of this study and helps to elucidate the sources and processes at a site which may be controlling the transport and fate of microorganic contaminants. Important aspects included contaminant source using co-contaminants and degradation products, groundwater/surface water interactions, a prominent feature being the absence of many compounds in the Chalk hyporheic zone. The results were consistent with the conceptual understanding of the hydrogeology of sites using other tracers, such as residence time and groundwater organic matter fluorescence.

Fingerprinting groundwater using microorganics has the potential to become a useful tool to help to characterise groundwater and contaminant movement at hydraulically complex sites, including the hyporheic zone. Given the diverse array of contaminants observed in both periurban setting such as that of the Thames floodplain in Oxford, and rural agricultural catchments such as Boxford this approach may also be widely applicable.

\section{Acknowledgements}

The work was funded by the Natural Environment Research Council (NERC) and by the Environment Agency. This paper is published with the permission of the Executive Director, British Geological Survey (NERC). The authors would like to thank Kate Griffiths, Katya Manamsa and Emily Crane of the British Geological Survey for their contribution to sample collection and Wayne Civil of the Environment Agency National Laboratory Service for analytical methodology information. 


\section{References}

Allen DJ, Darling WG, Gooddy DC, Lapworth DJ, Newell AJ, Williams AT, et al. Interaction between groundwater, surface water and the hyporheic zone in a Chalk stream: a case study from the River Lambourn, UK. Hydrol J 2010;5:1125-41.

Arias-Estévez M, López-Periago E, Martínez-Carballo E, Simal-Gándara J, Mejuto J-C, García-Río L. The mobility and degradation of pesticides in soils and the pollution of groundwater resources. Agriculture, Ecosystems \& Environment 2008;123:247-260.

Bagley DM, Gossett JM. Tetrachloroethene transformation to trichloroethene and cis-1,2dichloroethene by sulfate-reducing enrichment cultures. Appl Environ Microbiol 1990;56:2511-6.

Banzhaf S, Krein A, Scheytt T. Using selected pharmaceutical compounds as indicators for surface water and groundwater interaction in the hyporheic zone of a low permeability riverbank. Hydrol Proc In press.

Baran N, Lepiller M, Mouvet C. Agricultural diffuse pollution in a chalk aquifer (Trois Fontaines, France): Influence of pesticide properties and hydrodynamic constraints. J Hydrol 2008a;358:56-69.

Baran N, Lepiller M, Mouvet C. Agricultural diffuse pollution in a chalk aquifer (Trois Fontaines, France): Influence of pesticide properties and hydrodynamic constraints. J Hydrol 2008b;358:56-69.

Barnes KK, Christenson SC, Kolpin DW, Focazio MJ, Furlong ET, Zaugg SD, et al. Pharmaceuticals and other organic waste water contaminants within a leachate plume downgradient of a municipal landfill. Ground Water Monit Rev 2004;24:119-26.

Bazin I, Gadal A, Touraud E, Roig B. Hydroxy benzoate preservatives (parabens) in the environment: Data for environmental toxicity assessment. In: Fatta-Kassinos D, Bester K, Kümmerer K, editors. Xenobiotics in the urban water cycle. 16. Springer Netherlands, 2010, pp. 245-57.

Besse J-P, Garric J. Human pharmaceuticals in surface waters: Implementation of a prioritization methodology and application to the French situation. Toxicol Lett 2008;176:104-23.

Boulton AJ, Findlay S, Marmonier P, Stanley EH, Valett M. The functional significance of the hyporheic zone in streams and rivers. Ann Rev Ecol System 1998;29:51-81.

Boxall ABA, Fogg LA, Blackwell PA, Blackwell P, Kay P, Pemberton EJ, et al. Veterinary Medicines in the Environment. Rev Environ Contam Toxicol 2004;180:1-91.

Buerge IJ, Buser H-R, Kahle M, Müller MD, Poiger T. Ubiquitous occurrence of the artificial sweetener acesulfame in the aquatic environment: an ideal chemical marker of domestic wastewater in groundwater. Environ Sci Technol 2009;43:4381-5.

Buszka P, Yeskis D, Kolpin DW, Furlong E, Zaugg S, Meyer M. Waste-indicator and pharmaceutical compounds in landfill-leachate-affected ground water near Elkhart, Indiana, 2000-2002. Bull Environ Contam Toxicol 2009;82:653-9.

Celiz MD, Tso J, Aga DS. Pharmaceutical metabolites in the environment: Analytical challenges and ecological risks. Environ Toxicol Chem 2009;28:2473-84.

Christensen TH, Kjeldsen P, Bjerg PL, Jensen DL, Christensen JB, Baun A, et al. Biogeochemistry of landfill leachate plumes. Appl Geochem 2001;16:659-718.

Clara M, Strenn B, Kreuzinger N. Carbamazepine as a possible anthropogenic marker in the aquatic environment: investigations on the behaviour of carbamazepine in wastewater treatment and during groundwater infiltration. Water Res 2004;38:947-54.

Close ME. Survey of pesticides in New Zealand groundwaters, 1994. NZ J Marine Fresh Res 1996;30:455-61. 
Crane M, Handy R, Garrod J, Owen R. Ecotoxicity test methods and environmental hazard assessment for engineered nanoparticles. Ecotoxicol 2008;17:421-437.

Daughton CG. Non-regulated water contaminants: emerging research. Environ Impact Assess 2004;24:711-32.

Daughton CG, Ternes T. Pharmaceuticals and personal care products in the environment: agents of subtle change? Environ Health Perspect 2000;107:907-38.

Drewes JE, Reinhard M, Fox P. Comparing microfiltration-reverse osmosis and soil-aquifer treatment for indirect potable reuse of water. Water Res 2003;37:3612-21.

EC. Priority Substances Directive 2008/105/EC. $2008 . \quad \underline{\text { http://eur- }}$ lex.europa.eu/LexUriServ/LexUriServ.do?uri=OJ:L:2008:348:0084:0097:EN:PDF

EC. Review of priority substances under the WFD. 2011. http://www.eea.eionet.europa.eu/./library?l=/chemicals.../substances...

Ellis JB. Pharmaceutical and personal care products (PPCPs) in urban receiving waters. Environ Pollut 2006;144:184-9.

Engelhardt I, Piepenbrink M, Trauth N, Stadler S, Kludt C, Schulz M, et al. Comparison of tracer methods to quantify hydrodynamic exchange within the hyporheic zone. J Hydrol 2011;400:255-266.

Fent K, Weston AA, Caminada D. Ecotoxicology of human pharmaceuticals. Aquat Toxicol 2006;76:122-59.

Galassi S, Provini A, Halfon E. Risk assessment for pesticides and their metabolites in water. Int J Environ Anal Chem 1996;65:331-44.

Gasser G, Rona M, Voloshenko A, Shelkov R, Tal N, Pankratov I, et al. Quantitative evaluation of tracers for quantification of wastewater contamination of potable water sources. Environ Sci Technol 2010;44:3919-25.

Gilliom RJ. Pesticides in US streams and groundwater. Environ Sci Technol 2007;41:34083414.

Glassmeyer ST, Kolpin DW, Furlong E, Focazio MJ. Environmental presence and persistence of pharmaceuticals: an overview. In: Aga DS, editor. Fate of pharmaceuticals in the environment and in water treatment systems. CRC Press, Boca Raton, 2008, pp. 3-52.

Gooddy DC, Darling WG, Abesser C, Lapworth DJ. Using chlorofluorocarbons (CFCs) and sulphur hexafluoride $\left(\mathrm{SF}_{6}\right)$ to characterise groundwater movement and residence time in a lowland Chalk catchment. J Hydrol 2006;330:44-52.

Grünheid S, Amy G, Jekel M. Removal of bulk dissolved organic carbon (DOC) and trace organic compounds by bank filtration and artificial recharge. Water Res 2005;39:3219-28.

Halling-Sørensen B, Nors Nielsen S, Lanzky PF, Ingerslev F, Holten Lützhøft HC, Jørgensen SE. Occurrence, fate and effects of pharmaceutical substances in the environment- A review. Chemosphere 1998;36:357-93.

Heberer T, Adam M. Transport and attenuation of pharmaceutical residues during artificial groundwater replenishment. Environ Chem 2004;1:22-5.

Heberer T, Dünnbier U, Reilich C, Stan H-J. Detection of drugs and drug metabolites in ground water samples of a drinking water treatment plant Fresen Environ Bull 1997;6:438-43.

Heberer T, Massmann G, Fanck B, Taute T, Dünnbier U. Behaviour and redox sensitivity of antimicrobial residues during bank filtration. Chemosphere 2008;73:451-60.

Hilton M, Thomas KV, Ashton D. Targetted monitoring programme for pharmaceuticals in the aqueous environment Environment Agency R\&D Technical Report P6-012/6/TR, 2003. 
Hunt RJ, Borchardt MA, Richards KD, Spencer SK. Assessment of Sewer Source Contamination of Drinking Water Wells Using Tracers and Human Enteric Viruses. Environ Sci Technol 2010;44:7956-7963.

Huschek G, Hansen PD, Maurer HH, Krengel D, Kayser A. Environmental risk assessment of medicinal products for human use according to European Commission recommendations. Environ Toxicol 2004;19:226-40.

Jacobsen CS, Sørensen SR, Juhler RK, Brüsch W, Aamand J. Emerging contaminants in Danish groundwater. $2005 . \quad$ http://www.geus.dk/programareas/water/denmark/rapporter/geus_rap_2005_49-uk.htm

Kasprzyk-Hordern B, Dinsdale RM, Guwy AJ. The occurrence of pharmaceuticals, personal care products, endocrine disruptors and illicit drugs in surface water in South Wales, UK. Water Res 2008;42:3498-518.

Katz BG, Griffin DW, Davis JH. Groundwater quality impacts from the land application of treated municipal wastewater in a large karstic spring basin: Chemical and microbiological indicators. Sci Total Environ 2009;407:2872-86.

Kjaer J, Olsen P, Henriksen T, Ullum M. Leaching of metribuzin metabolites and the associated contamination of a sandy Danish aquifer. Environ Sci Technol 2005;39:8374-81.

Kolpin DW, Barbash JE, Gilliom RJ. Pesticides in ground water of the United States, 19921996. Ground Water 2000;38:858-63.

Kolpin DW, Schnoebelen DJ, Thurman EM. Degradates provide insight to spatial and temporal trends of herbicides in ground water. Ground Water 2004;42:601-8.

Kümmerer K. The presence of pharmaceuticals in the environment due to human use present knowledge and future challenges. J Environ Manage 2009;90:2354-66.

Lam M, Young C, Brain R, Johnson D, Hanson M, Wilson C, et al. Aquatic persistence of eight pharmaceuticals in a microcosm study. Environ Toxicol Chem 2004;23:143140.

Lapworth DJ, Baran N, Stuart ME, Ward RS. Emerging organic contaminants in groundwater: A review of sources, fate and occurrence. Environ Pollut 2012;163:287303.

Lapworth DJ, Gooddy DC, Allen D, Old GH. Understanding groundwater, surface water, and hyporheic zone biogeochemical processes in a Chalk catchment using fluorescence properties of dissolved and colloidal organic matter. J Geophys Res Biogeosci 2009;114:G00F02.

Lapworth DJ, Stolpe B, Williams PJ, Gooddy DC, Lead JR. Characterization of suboxic groundwater colloids using a multi-method approach. Environ Sci Technol 2013;47:2554-61.

Lewandowski J, Putschew A, Schwesig D, Neumann C, Radke M. Fate of organic micropollutants in the hyporheic zone of a eutrophic lowland stream: Results of a preliminary field study. Sci Total Environ 2011;409:1824-35.

Lindsey ME, Meyer M, Thurman EM. Analysis of trace levels of sulfonamide and tetracycline antimicrobials in groundwater and surface water using solid-phase extraction and liquid chromatography/mass spectrometry. Anal Chem 2001;73:46406.

Macdonald DMJ, Griffiths KJ, Lapworth DJ, Williams PJ, Stuart ME, Gooddy DG. Hydrochemical characterisation of a peri-urban floodplain: initial findings British Geological Survey Internal Report IR/12/049, 2012.

Macdonald DMJ, other, other. Please let me know. 2013. 
Pal A, Gin KY-H, Lin AY-C, Reinhard M. Impacts of emerging organic contaminants on freshwater resources: Review of recent occurrences, sources, fate and effects. Sci Total Environ 2010;408:6062-9.

Parsons F, Wood PR, DeMarco J. Transformations of tetrachloroethene and trichloroethene in microcosms and groundwater. J Am Water Works Assoc 1984;76:56-9.

Parsons TW, Thomson TJ. Methaqualone as a hypnotic. Brit Med J 1961;5220:171-3.

Petrović M, Gros M, Barceló D. Multi-residue analysis of pharmaceuticals in wastewater by ultra-performance liquid chromatography-quadrupole-time-of-flight mass spectrometry. J Chromatogr A 2006;1124:68-81.

Rabiet M, Togola A, Brissaud F, Seidel J-L, Budzinski H, Elbaz-Poulichet F. Consequences of treated water recycling as regards pharmaceuticals and drugs in surface and ground waters of a medium-sized Mediterranean catchment. Environ Sci Technol 2006;40:5282-8.

Richardson SD, Ternes TA. Water analysis: emerging contaminants and current issues. Anal Chem 2011;83:4614-48.

Ritter WF. Pesticide contamination of ground water in the United States: A review. Journal of Environmental Science and Health, Part B 1990;25:1-29.

Sabel GV, Clark TP. Volatile organic compounds as indicators of municipal solid waste leachate contamination. Waste Manage Res 1984;2:119-30.

Sacher F, Lange FT, Brauch H-J, Blankenhorn I. Pharmaceuticals in groundwaters: Analytical methods and results of a monitoring program in Baden-Württemberg, Germany. J Chromatogr A 2001;938:199-210.

Schwarzenbach RP, Escher BI, Fenner K, Hofstetter TB, Johnson CA, von Gunten U, et al. The challenge of micropollutants in aquatic systems. Science 2006;313:1072-7.

Slack RJ, Gronow JR, Hall DH, Voulvoulis N. Household hazardous waste disposal to landfill: Using LandSim to model leachate migration. Environ Pollut 2007;146:501-9.

Snyder SA, Leising J, Westerhoff P, Yoon Y, Mash H, Vanderford B. Biological and physical attenuation of endocrine disruptors and pharmaceuticals: Implications for water reuse. Ground Water Monit Rem 2004;24:108-18.

Somasundaram L, Coats JR. Pesticide transformation products in the environment. In: Somasundaram L, Coats JR, editors. Pesticide Transformation Products. 459. American Chemical Society, Washington DC, 1991, pp. 2-9.

Stan H-J, Herberer T, Linkerhägner M. Occurrence of clofibric acid in the aquatic system -is the use in human medical care the source of the contamination of surface, ground and drinking water? . Vom Wasser 1994;83:57-68.

Stan H-J, Linkerhägner M. Identification of 2-(4-chlorphenoxy)-2-methyl-propionic acid in groundwater with GC-AED and GC-AED and GC-MS. Vom Wasser 1992;79:75-88.

Stuart M, Lapworth DJ, Crane E, Hart A. Review of risk from potential emerging contaminants in UK groundwater. Sci Total Environ 2012;416:1-21.

Tappe W, Groeneweg J, Jantsch B. Diffuse atrazine pollution in German aquifers. Biodegradation 2002;13:3-10.

Thompson WL, Johnson AD, Maddrey WL. Diazepam and paraldehyde for treatment of severe delirium tremens: A controlled trial. Ann Int Med 1975;82:175-80.

Tufenkji N, Ryan JN, Elimelech M. Peer reviewed: The promise of bank filtration. Environ Sci Technol 2002;36:422A-8A.

Van Stempvoort DR, Roy JW, Brown SJ, Bickerton G. Artificial sweeteners as potential tracers in groundwater in urban environments. J Hydrol 2011;401:126-33.

Verlicchi P, Galletti A, Petrovic M, Barceló D. Hospital effluents as a source of emerging pollutants: an overview of micropollutants and sustainable treatment options. J Hydrol 2010;389:416-28. 
Walls D, Smith PG, Mansell MG. Pesticides in groundwater in Britain. Int J Environ Health Rev 1996;6:55-62.

Watkinson AJ, Murby EJ, Kolpin DW, Costanzo SD. The occurrence of antibiotics in an urban watershed: From wastewater to drinking water. Sci Total Environ 2009;407:2711-23.

Zeng T, Ziegelgruber KL, Chin Y-P, Arnold WA. Pesticide processing potential in prairie pothole porewaters. Environ Sci Technol 2011;45:6814-6822.

Zenker MJ, Borden RC, Barlaz MA. Occurrence and treatment of 1,4-dioxane in aqueous environments. Environ Eng Sci 2004;20:423-32.

Zheng W, Wang X, Tian D, Jiang S, Andersen ME, He G, et al. Water pollutant fingerprinting tracks recent industrial transfer from coastal to inland China: A case study. Sci Rep 2013;3. 

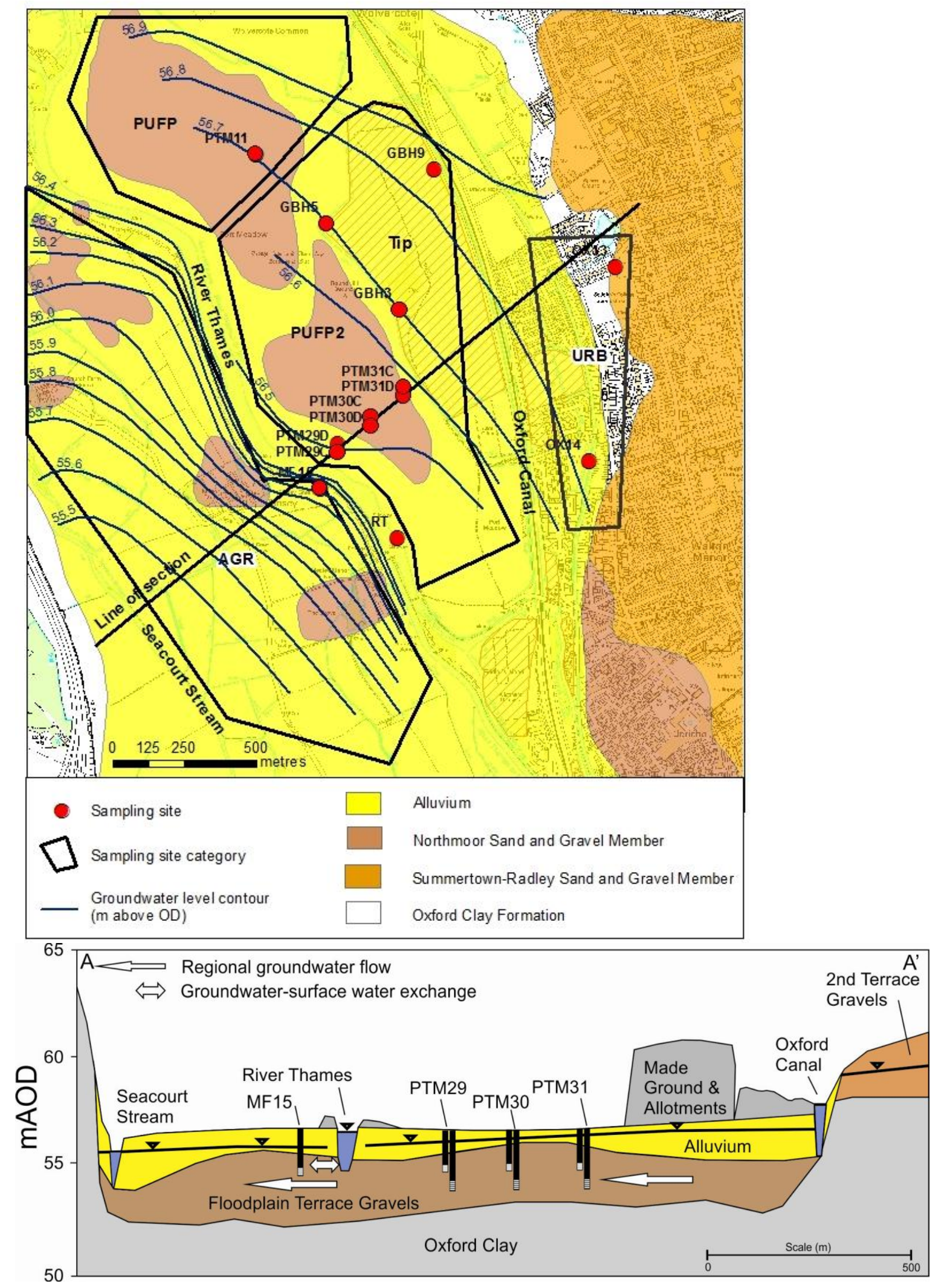

Figure 1. The Oxford Observatory: a) site plan showing sampling points and b) sketch cross-section along the line of section shown in a) (adapted from Macdonald et al. (2012) 

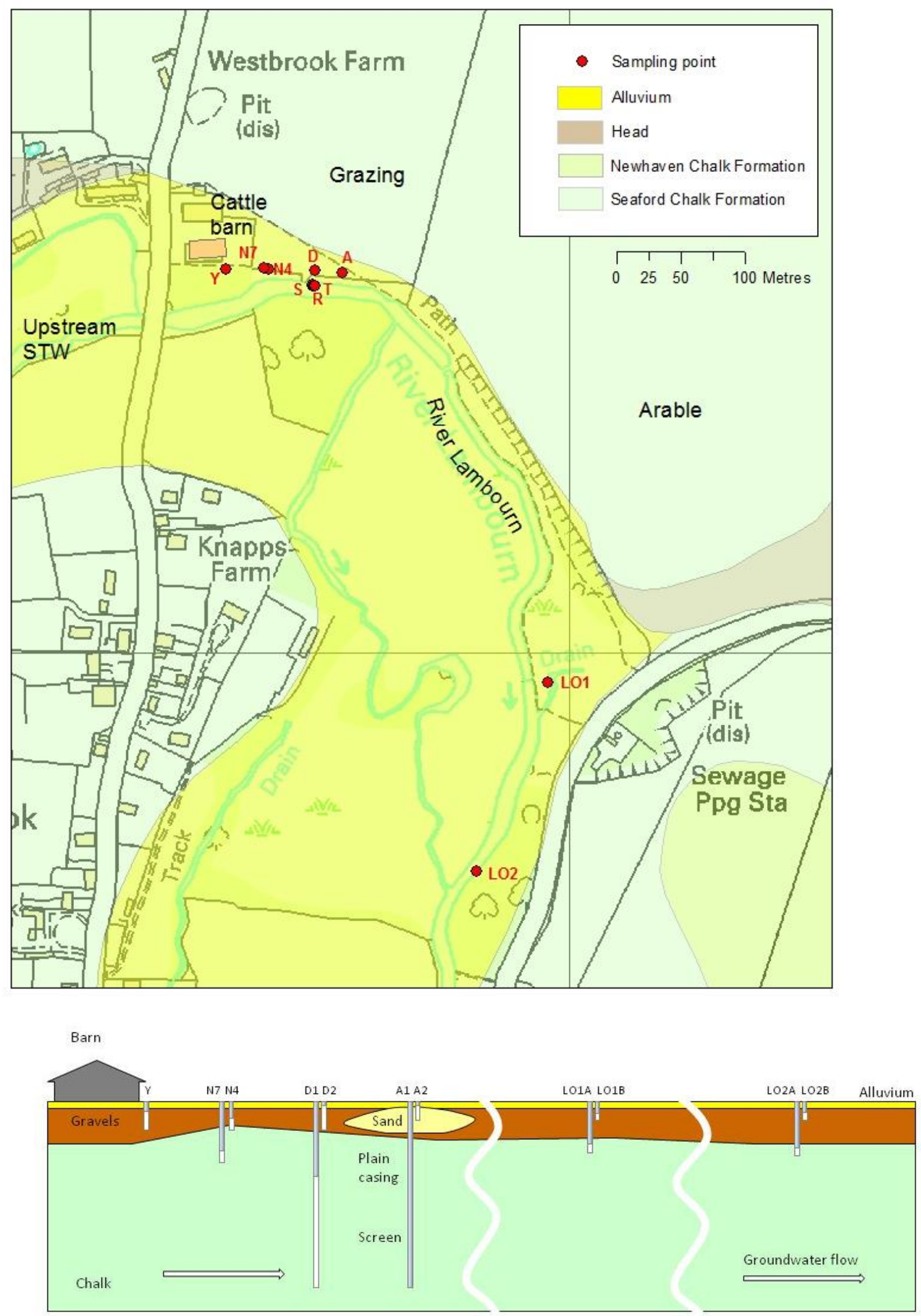

Figure 2. The Boxford Observatory: a) site plan showing sampling pints and b) sketch cross-section northwest-southeast along the River Lambourn 


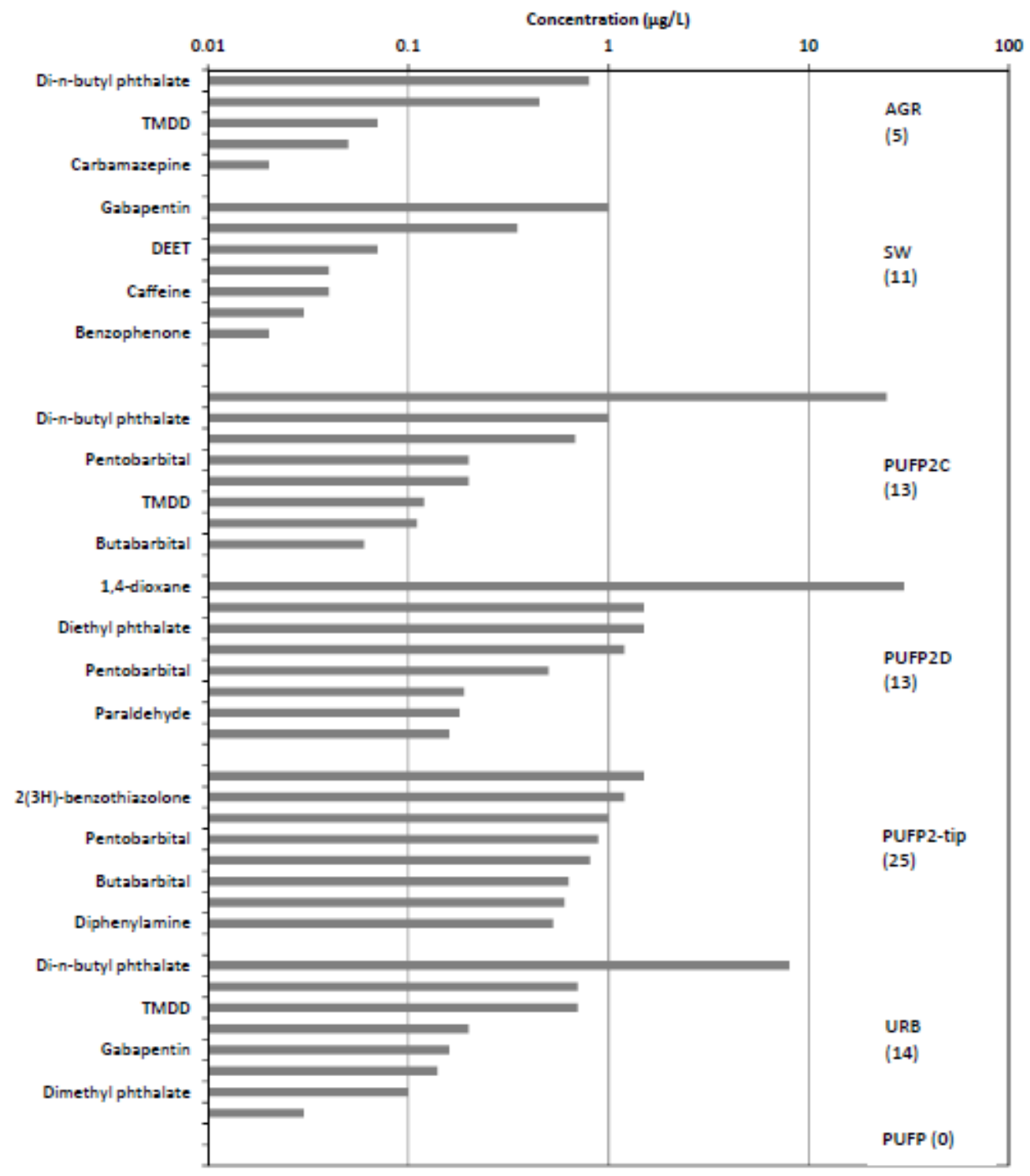

Figure 3. Median concentrations of top eight components per zone west - east at Oxford, First round. Total number of compounds per zone shown in parentheses. 


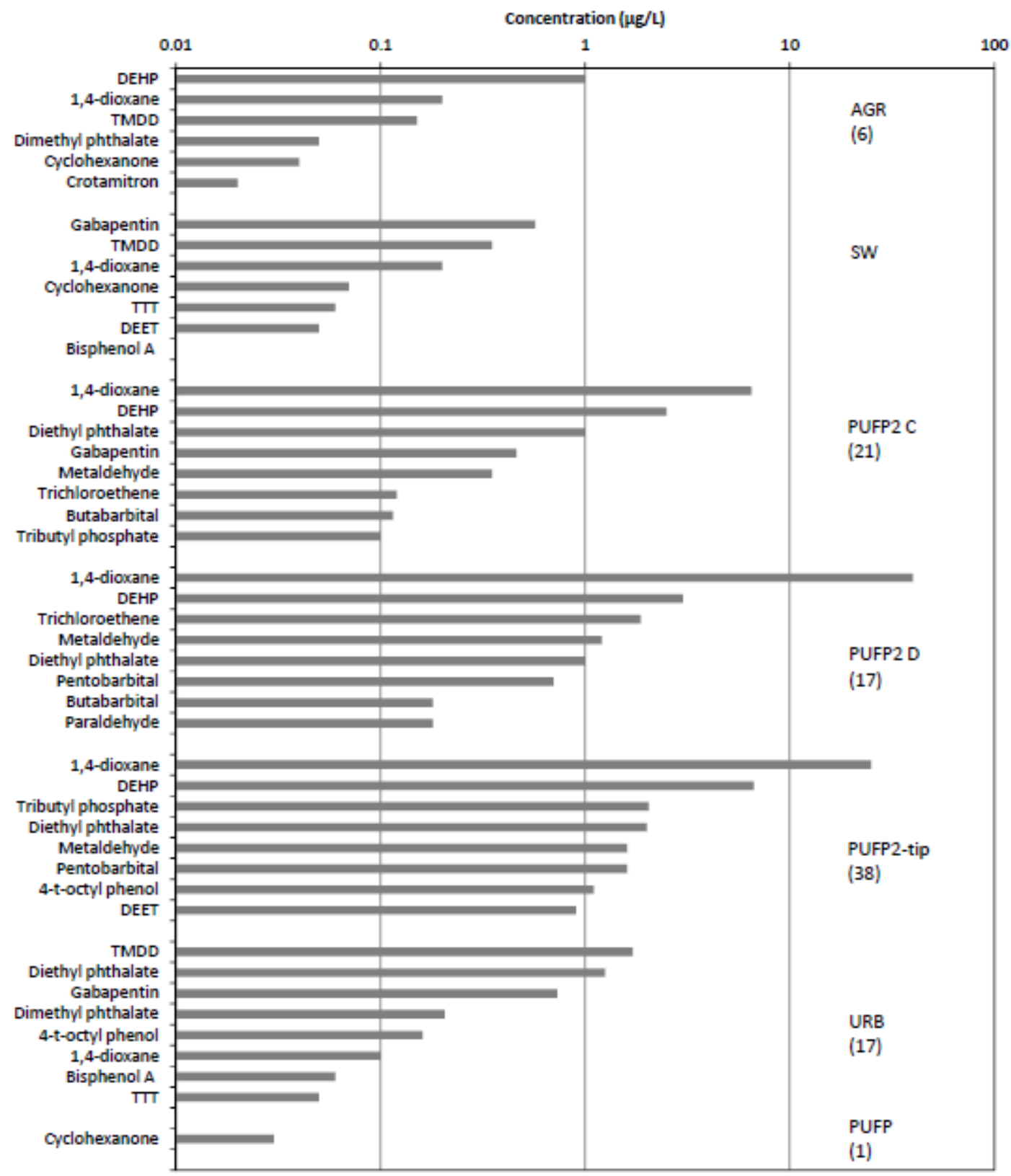

Figure 4. Median concentrations of top eight components per zone west - east at Oxford ,Second round. Total number of compounds per zone shown in parentheses. 


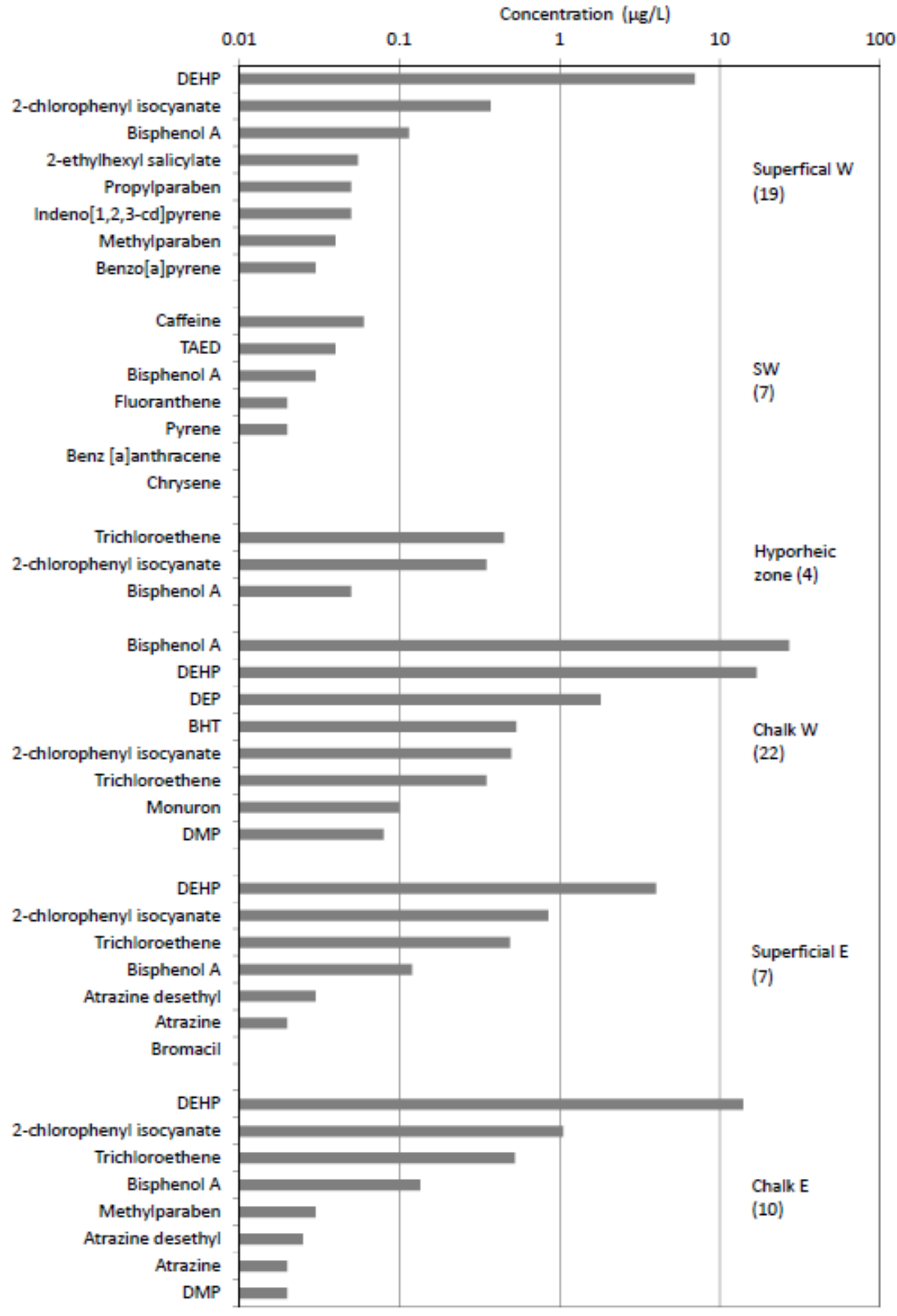

Figure 5. Median concentrations of top eight components per zone west - east at Boxford, First round. Total number of compounds per zone shown in parentheses. 


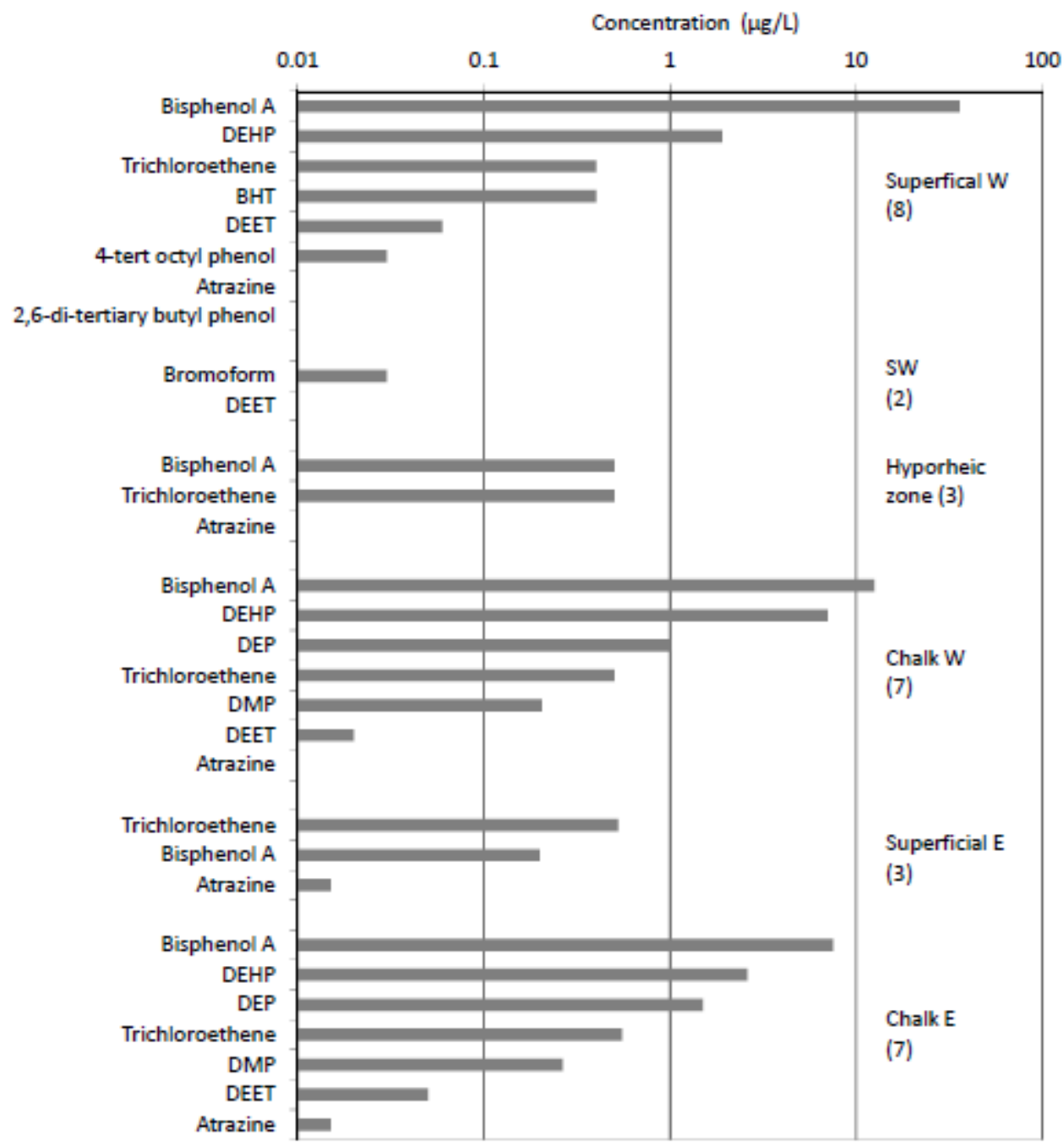

Figure 6. Median concentrations of top eight components per zone west - east at

Boxford, Second round. Total number of compounds per zone shown in parentheses. 


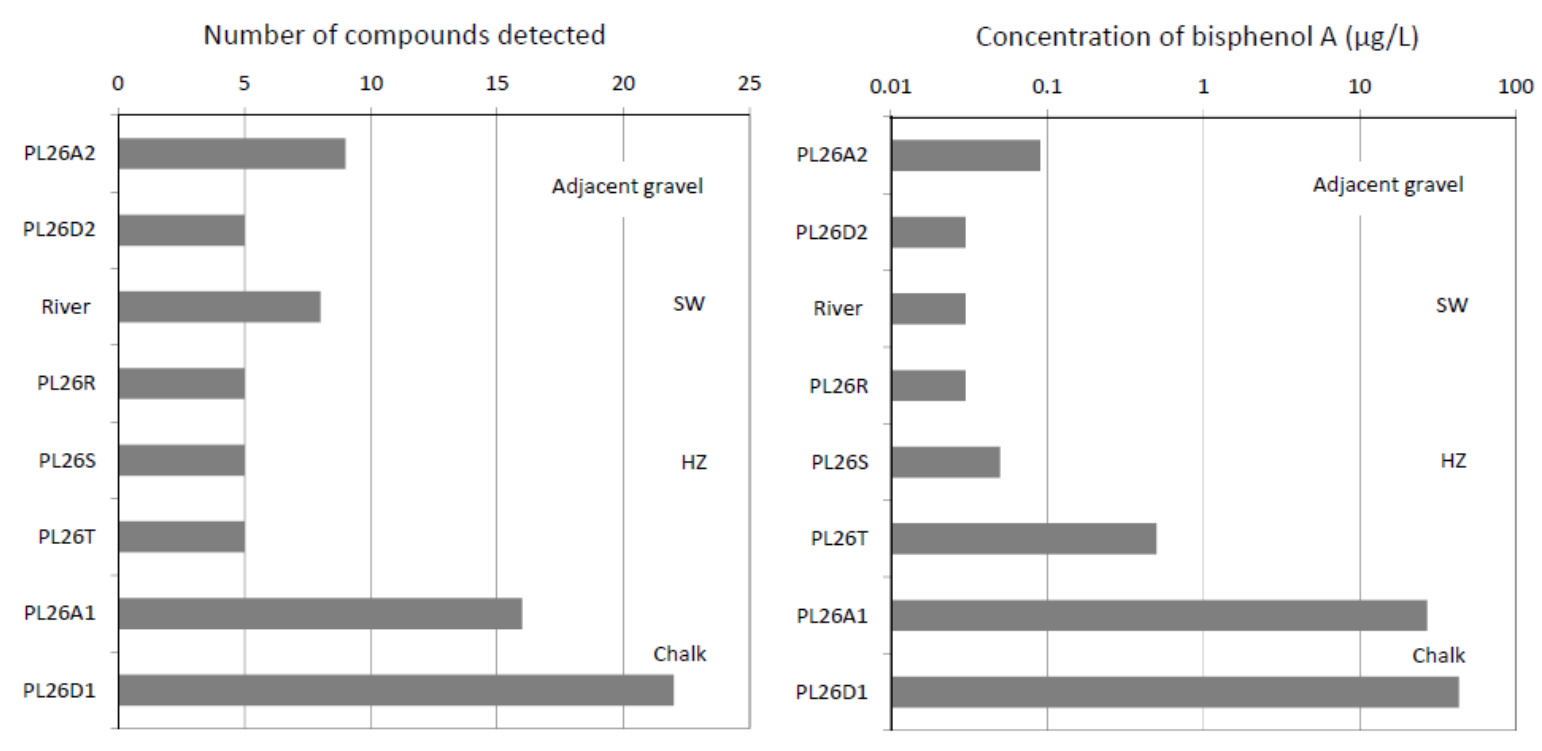

Figure 7. Vertical profiles in adjacent gravels and below the river Lambourn, Boxford for: a) total number of compounds and b) bisphenol $\mathrm{A}$
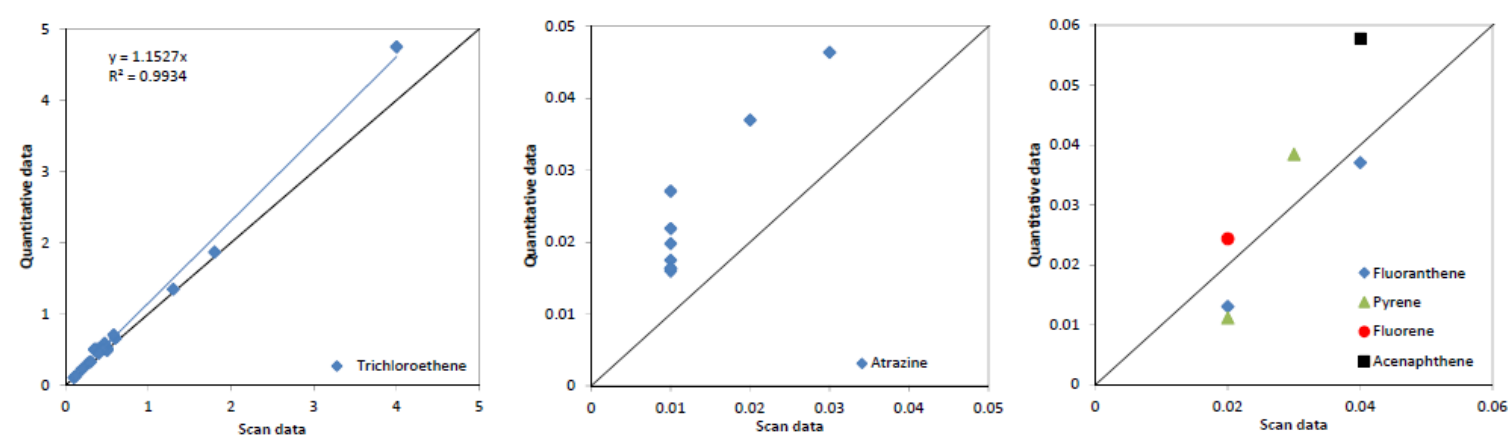

Figure S1 Crossplots of selected analytes of scanning method data versus quantitative method data 
Table 1. Details of sites used by the study

\begin{tabular}{|c|c|c|c|c|}
\hline Site ID & Aquifer description & $\begin{array}{l}\text { Open } \\
\text { interval } \\
(\mathbf{m} \text { bgl }) \\
\end{array}$ & Site category & Landuse \\
\hline \multicolumn{5}{|l|}{ Oxford } \\
\hline GBH3 & Gravel & & PUFP2- tip & Waste tip \\
\hline GBH5 & Gravel & & PUFP2- tip & Waste tip \\
\hline GBH9 & Gravel & & PUFP2- tip & Waste tip \\
\hline MF15 & Gravel & $1.10-1.65$ & AGR & Agriculture \\
\hline OX13 & Gravel & $2.13-2.98$ & URB & Urban \\
\hline OX14 & Gravel & $2.05-2.92$ & URB & Urban \\
\hline PTM11 & Gravel & $2.98-3.83$ & PUFP & Floodplain \\
\hline PTM29C & Gravel & 1.8 & PUFP2C & Leachate plume \\
\hline PTM29D & Gravel & $3.21-3.71$ & PUFP2D & Leachate plume \\
\hline PTM30C & Gravel & 1.81 & PUFP2C & Leachate plume \\
\hline PTM30D & Gravel & $3.30-3.80$ & PUFP2D & Leachate plume \\
\hline PTM31C & Gravel & 1.78 & PUFP2C & Leachate plume \\
\hline PTM31D & Gravel & $3.32-3.82$ & PUFP2D & Leachate plume \\
\hline River Thames & Surface water & & SW & \\
\hline \multicolumn{5}{|l|}{ Boxford } \\
\hline LO1A & Chalk & $5.15-7.00$ & Chalk E & Agriculture \\
\hline LO1B & Gravel & $2.15-3.00$ & Superficial E & Agriculture \\
\hline LO2A & Chalk & $6.90-7.75$ & Chalk E & Agriculture \\
\hline $\mathrm{LO} 2 \mathrm{~B}$ & Gravel & $2.05-2.90$ & Superficial E & Agriculture \\
\hline N4 & Gravel & $2.66-3.63$ & \begin{tabular}{|l|} 
Chalk W \\
\end{tabular} & Agriculture/ barn \\
\hline N7 & Chalk & $6.9-7.33$ & Chalk W & Agriculture \\
\hline PL26A1 & Chalk & $13.2-25$ & Chalk W & Agriculture \\
\hline PL26A2 & Gravel & $0-1.78$ & Superficial W & Agriculture \\
\hline PL26D1 & Chalk & $10.7-25$ & Chalk W & Agriculture \\
\hline PL26D2 & Gravel & $0-3.80$ & Superficial W & Agriculture \\
\hline PL26R & Gravels - hyporheic & $0.4-0.6$ & $\mathrm{HZ}$ & Agriculture/STW \\
\hline PL26S & Gravels - hyporheic & $1.4-1.6$ & $\mathrm{HZ}$ & Agriculture \\
\hline PL26T & Gravels - hyporheic & $2.4-2.6$ & $\mathrm{HZ}$ & Agriculture \\
\hline PL26Y & Gravel & $1.5-3.55$ & Superficial W & Agriculture/ barn \\
\hline River Lambourn & Surface water & & SW & \\
\hline
\end{tabular}


Table 2. Detection frequency and maximum concentrations detected at the Oxford Observatory for 2011 and 2012 by GCMS targeted scanning

\begin{tabular}{|c|c|c|c|c|}
\hline \multirow[t]{2}{*}{ Compound } & \multicolumn{2}{|c|}{$\begin{array}{c}\text { Number of } \\
\text { detections }\end{array}$} & \multicolumn{2}{|c|}{$\begin{array}{c}\text { Max concentration } \\
(\mu \mathrm{g} / \mathrm{L})\end{array}$} \\
\hline & 2011 & 2012 & 2011 & 2012 \\
\hline 1,2-dichlorobenzene & 2 & 3 & 0.04 & 0.04 \\
\hline 1,3,5-triallyl-,1,3,5-triazine-2,4,6-trione (TTT) & 2 & 2 & 0.8 & 0.7 \\
\hline 1,3-dichlorobenzene & 2 & 3 & 0.04 & 0 \\
\hline 1,4-dioxane & 6 & 12 & 0.03 & 0.06 \\
\hline 2(3H)-benzothiazolone & 1 & 1 & 42 & 50 \\
\hline 2,4,7,9-tetramethyl-5-decyne-4,7-diol (TMDD) & 11 & 11 & 1.2 & 0.7 \\
\hline 2-Chlorophenyl isocyanate & 2 & 0 & 0.7 & 1.7 \\
\hline 4-t-octyl phenol & 2 & 2 & 0.83 & 0 \\
\hline Acenaphthene & 1 & 1 & 0.6 & 1.1 \\
\hline Anthracene & 1 & 0 & 0.05 & 0.04 \\
\hline Benzenesulfonamide & 0 & 3 & 0.01 & 0 \\
\hline Benzophenone & 6 & 6 & 0 & 51 \\
\hline Bis(2-chloroethyl) ether & 0 & 1 & 0.17 & 0.18 \\
\hline Bis(2-ethylhexyl)phthalate (DEHP) & 1 & 6 & 0 & 0.06 \\
\hline Bisphenol A & 3 & 5 & 5 & 12 \\
\hline Butabarbital & 8 & 8 & 0.7 & 2.2 \\
\hline Butylated hydroxyanisole (BHA) & 0 & 2 & 0.97 & 1.6 \\
\hline Butylated hydroxytoluene (BHT) & 0 & 2 & 0 & 0.09 \\
\hline Caffeine & 1 & 0 & 0 & 0.12 \\
\hline Carbamazepine & 3 & 1 & 0.04 & 0 \\
\hline Chlorobenzene & 2 & 4 & 0.04 & 0.03 \\
\hline Crotamitron & 4 & 6 & 0.5 & 0.65 \\
\hline Cyclohexanone & 2 & 9 & 0.26 & 0.5 \\
\hline Cyclohexylphthalate & 0 & 1 & 0.2 & 0.18 \\
\hline Dibenzofuran & 2 & 0 & 0 & 0.77 \\
\hline Dicyclohexyl phthalate & 1 & 0 & 0.01 & 0 \\
\hline Diethyl phthalate (DEP) & 2 & 11 & 0.4 & 0 \\
\hline Dimethyl phthalate & 11 & 12 & 1.5 & 2 \\
\hline Di-n-butyl phthalate & 5 & 0 & 0.64 & 0.29 \\
\hline Diphenyl ether & 0 & 1 & 8 & 0 \\
\hline Diphenylamine & 2 & 2 & 0 & 0.01 \\
\hline Fluoranthene & 2 & 4 & 1 & 0.7 \\
\hline Fluorene & 1 & 1 & 0.02 & 0.02 \\
\hline Gabapentin & 2 & 3 & 0.03 & 0.02 \\
\hline Metaldehyde & 10 & 9 & 1 & 0.73 \\
\hline Methaqualone & 1 & 2 & 5.5 & 3.3 \\
\hline
\end{tabular}




\begin{tabular}{|l|c|c|c|c|}
\hline N,N-diethyl-m-toluamide (DEET) & 9 & 11 & 0.3 & 0.27 \\
\hline N-butyl benzene sulfonamide (BBSA) & 14 & 12 & 0.64 & 0.9 \\
\hline N-ethyl-2-methyl benzene sulfonamide & 2 & 0 & 230 & 561 \\
\hline N-ethyl-4-methyl benzene sulfonamide & 2 & 0 & 2.5 & 0 \\
\hline Paraldehyde & 8 & 8 & 1 & 0 \\
\hline Pentobarbital & 9 & 9 & 0.4 & 0.32 \\
\hline Phenanthrene & 1 & 0 & 2 & 2.9 \\
\hline Pyrene & 2 & 3 & 0.02 & 0 \\
\hline sec-butylbenzene & 1 & 0 & 0.02 & 0.1 \\
\hline tert-butylbenzene & 0 & 1 & 0 & 0.02 \\
\hline Tributyl phosphate & 2 & 3 & 1.2 & 3.8 \\
\hline Trichloroethene & 5 & 7 & 3.5 & 4 \\
\hline Triphenyl phosphate & 2 & 0 & 0.5 & 0 \\
\hline Triphenylphosphine oxide & 0 & 2 & 0 & 0.43 \\
\hline Tris-(1,3-dichloroisopropyl) phosphate & 0 & 1 & 0 & 0.12 \\
\hline
\end{tabular}


Table 3. Detection frequency and maximum concentrations detected at the Boxford Observatory for January and August 2012 by GCMS targeted scanning

\begin{tabular}{|c|c|c|c|c|}
\hline \multirow[t]{2}{*}{ Compound } & \multicolumn{2}{|c|}{$\begin{array}{l}\text { Number of } \\
\text { detections }\end{array}$} & \multicolumn{2}{|c|}{$\begin{array}{c}\text { Max concentration } \\
(\mu \mathrm{g} / \mathrm{L})\end{array}$} \\
\hline & Jan-12 & Aug-12 & Jan-12 & Aug-12 \\
\hline 1(3H)-isobenzofuranone & 3 & 0 & 0.04 & 0 \\
\hline 2,6-di-tertiary butyl phenol & 0 & 1 & 0 & 0.01 \\
\hline 2-chlorophenyl isocyanate & 13 & 0 & 1.2 & 0 \\
\hline 2-ethylhexyl salicylate & 2 & 0 & 0.06 & 0 \\
\hline 4-tert octyl phenol & 0 & 1 & 0 & 0.03 \\
\hline Atrazine & 10 & 10 & 0.03 & 0.02 \\
\hline Atrazine desethyl & 3 & 0 & 0.03 & 0 \\
\hline Benz [a]anthracene & 3 & 0 & 0.02 & 0 \\
\hline Benzo[a]pyrene & 2 & 0 & 0.03 & 0 \\
\hline Benzo[b]fluoranthene & 1 & 0 & 0.03 & 0 \\
\hline Benzo[g,h,i]perylene & 1 & 0 & 0.02 & 0 \\
\hline Benzo[k]fluoranthene & 1 & 0 & 0.01 & 0 \\
\hline Benzophenone & 2 & 0 & 0.02 & 0 \\
\hline Bis (2-ethylhexyl)phthalate (DEHP) & 10 & 8 & 46 & 9 \\
\hline Bisphenol A & 15 & 7 & 43 & 36 \\
\hline Bromacil & 2 & 0 & 0.01 & 0 \\
\hline Bromoform & 0 & 1 & 0 & 0.03 \\
\hline Butylated hydroxytoluene (BHT) & 2 & 1 & 0.95 & 0.4 \\
\hline Caffeine & 9 & 0 & 0.1 & 0 \\
\hline Chloroxylenol & 3 & 0 & 0.01 & 0 \\
\hline Chrysene & 3 & 0 & 0.02 & 0 \\
\hline Cyclohexanone & 1 & 0 & 0.05 & 0 \\
\hline Diethylphthalate (DEP) & 1 & 2 & 1.8 & 1.5 \\
\hline Dimethylphthalate (DMP) & 4 & 4 & 0.15 & 0.38 \\
\hline Fluoranthene & 5 & 0 & 0.04 & 0 \\
\hline Indeno[1,2,3-cd]pyrene & 1 & 0 & 0.05 & 0 \\
\hline Methylparaben & 6 & 0 & 0.08 & 0 \\
\hline Monuron & 1 & 0 & 0.1 & 0 \\
\hline $\mathrm{N}, \mathrm{N}, \mathrm{N}^{\prime}, \mathrm{N}^{\prime}$-tetraacetylethylenediamine & 1 & 0 & 0.04 & 0 \\
\hline N,N-diethyl-m-toluamide (DEET) & 3 & 4 & 0.06 & 0.06 \\
\hline N-butyl-benzenesulfonamide (BBSA) & 15 & 14 & 240 & 6 \\
\hline Phenanthrene & 1 & 0 & 0.01 & 0 \\
\hline Propylparaben & 5 & 0 & 0.07 & 0 \\
\hline Pyrene & 4 & 0 & 0.03 & 0 \\
\hline Simazine & 1 & 0 & 0.01 & 0 \\
\hline Trichloroethene & 14 & 14 & 0.6 & 0.6 \\
\hline
\end{tabular}


